Please note that all letters must be typed. Priority will be given to those that are less than $\mathbf{5 0 0}$ words long. All authors must sign the letter, which may be shortened or edited for reasons of space or clarity. All letters received are acknowledged.

\section{Routine check-ups}

Sir, - The BDA Press Release (17 April 2000) in response to my Jean Todd Lecture at the Dental Practice Board Conference in April says that 'the public are now advised by their dentists to go for check-ups less often than in the past - that is, at least once a year - unless they need to go more often.' They also state that the recent Adult Dental Health Survey found that around three quarters of the public has visible plaque. Regarding X-rays, they quote the RCS report which says that routine radiographs for low-risk people need not be taken more often than once every two years.

In my lecture I said: 'If NICE recommends that unless a person can be defined as high-risk, the intervals between dental examinations should be 18 months for under 18-year-olds and 2-3 years for adults, the numbers of dental examinations on adults would be reduced by about half, assuming that approximately half the adults currently attending are regular annual attenders. There would be about six to 10 million fewer dental visits a year and a saving of between $\mathfrak{E} 50$ to $\mathfrak{E} 120 \mathrm{~m}$ considering that fewer radiographs would be taken.'

On scaling and polishing teeth, I said: 'Over 13 million scaling and polishings are done annually on adults in England and Wales. Yet there is no evidence that there is any health gain from such procedures. In a state-of-the-science review of mechanical oral hygiene practices, Frandsen (1986) concluded that the optimal frequency and starting age for scaling and polishing has not been determined. Scaling, polishing, root planing, and surgical treatment of shallow periodontal pockets results in permanent loss of attachment. A recent systematic review of 144 studies on the effectiveness of scale and polish carried out more frequently than once a year compared to once a year, concluded that there was very little gain in periodontal health from more frequent scalings. Add to these conclusions the findings in the systematic review that chairside dental health education was ineffective in reducing periodontal disease or caries, then there is little scientific justification for prophylaxis and chairside dental health education. Once a year or so, cleaning has questionable health benefit. Yet, that item costs about as much as all NHS inlays and crowns in England and Wales in 1997/98 (DPB 1998), $\mathfrak{E} 113.3 \mathrm{~m}$ compared to $\mathfrak{E} 120.2 \mathrm{~m}$. That is 13.2 per cent of total GDS annual expenditure for adults.'

I did not state that people should not go to the dentist; merely that the intervals between recalls should be increased and that scale and polishes should be done less frequently. Longer recall intervals would logically mean taking fewer $\mathrm{X}$-rays. Therefore, if we want to assess whether there is any detriment to dental health by increasing the recall intervals, we should compare Regular Attenders (RA) with Occasional Attenders (OA). An analysis of the results from the recent Adult Dental Health Survey - Oral Health in the United Kingdom $1998^{3}$ indicates that there is very little difference in dental health between adults who go regularly or occasionally. Fifty-eight per cent had made no dental visit in the past five years, 34 per cent had made 3-4 visits and six per cent made 5-9 visits in the past five years.

What is most interesting is that OA's had three or more sound teeth (no fillings) than RA's. OA's also had more teeth present and fewer missing teeth (see Table 1 below).

OA's had less periodontal disease than RA's (39 per cent of OAs versus 43 per cent RAs with loss of attachment of $4 \mathrm{~mm}$ or greater and the differences in plaque (68 per cent in RA's versus 72 per cent in OAs) and calculus (68 per cent in RA's versus 75 per cent in OAs) are small and can be explained by the fact that because OA's had more teeth, there were more surfaces to get plaque and calculus (Table 3.0.3 of the Survey).

In summary, there is no evidence that increasing the interval for dental check-ups to one year or longer had any significant adverse effect on dental status. On the contrary, OA's had more sound unattacked teeth and fewer teeth with deep periodontal pockets.

The BDA state that people are now being advised by their dentists to go for check-ups less often than in the past. Fifty-nine per cent of dentate adults go for regular check ups and 82 per cent of regular attenders have

\begin{tabular}{|l|ccccc|}
\hline Table I & \multicolumn{5}{|c|}{$\begin{array}{l}\text { Difference between treatment for Regular Attenders }(\mathrm{R} / \mathrm{A}) \text { and Occasional } \\
\text { Attenders }(\mathrm{OA})(\text { Kelly et al } 2000)\end{array}$} \\
\hline & Teeth present & Missing & Decay & Filled & Sound \\
\hline RA & 24.0 & 7.1 & 1.1 & 8.0 & 14.6 \\
\hline OA & 26.3 & 5.7 & 1.4 & 5.1 & 17.5 \\
\hline
\end{tabular}

visited a dentist in the last six months - a further 15 per cent have made visits between six months and up to one year (Table 6.1.11 of the Survey). This suggests that either the dentists are not advising their adult patients to go for check ups less often, the 6-month recall was the previous recall interval, or that large percentages of patients, who are now much more dentally healthy than before, are deciding to go for the outdated 6-monthly recall.

So, contrary to what the BDA stated, there is some dental health gain in extending recall intervals to $2-3$ years for adults, as argued in the Jean Todd Lecture. Issuing press reports which do not tell the true story is unbecoming of a professional body which prides itself on being evidence based.

\section{A. Sheiham \\ Professor of Dental Public Health, University College London Medical School}

1 DPB (1998) Digest of Statistics 1997/98 Part 1. Detailed analysis of GDS Treatment items. Dental Practice Board

2 Frandsen A, Loe H, Kleinman D V. Mechanical oral hygiene practises. In Dental plaque control measures and oral hygiene practices (1986). p.93-116. Oxford: IRL Press.

3 Kelly M, Steele J, Nuttall N, Bradnock G, Morris J, Nunn J, Pine C, Pitts N, Treasure E, White D. (2000) Adult Dental Health Survey. Oral Health in the United Kingdom 1998. HMSO, London.

Michael Watson, BDA Special Advisor responds: First we must make clear that the BDA Press Release of 17 April 2000, to which Professor Sheiham refers, was not in response to his Jean Todd Lecture at the Dental Practice Board Conference. It was issued as a result of damaging media stories which appeared in a Sunday newspaper the previous day and subsequent interviews given by Professor Sheiham on the radio. Unlike the Sunday newspaper we had no advance copy of his speech. Our press release was responding to the spin put on the speech by the newspaper, not the substance of the speech. The spin was to the effect that greedy dentists were doing unnecessary work for financial gain. We owe it to our members and the profession to rebut such stories in the most vigorous terms.

Turning to the figures he quotes in his letter, from the 1998 Adult Dental Health Survey, he is being somewhat selective in his choice of statistics, in comparing those who attend for an occasional check up with those who have regular check-ups. Chapter 6.1 and Tables 6.1.9 and 6.1.11 of the Survey make it clear that the numbers claiming to be the former are far fewer than those claiming to attend regularly. Over half of the occasionals attend at least once a year, which some would consider put them in the regular category.

The significant difference in attendance is 


\section{OPINION $\underline{\text { letters }}$}

between those who attend regularly and those who attend only when in pain. The latter have one fewer tooth present (24.0 to 24.9), one more tooth missing (8.0 to 7.1); more have visible plaque (80 per cent against 68 per cent, more calculus (82 per cent: 68 per cent) and more of them (10 per cent: seven per cent) have serious loss of attachment (>6mm).

A more recent report into the oral health of young people (National Diet and Nutrition Survey: Report of the Oral Health Survey) shows that those who attend regularly were less likely to have caries experience (53 per cent) than those who attend only in pain or never ( 75 per cent). Similar figures are found for those with active caries. This does not prove cause and effect of course, but neither, with respect, do Professor Sheiham's figures.

The BDA did state that people are now being advised by dentists to go for check-ups less often than in the past and the Adult Dental Health Survey would suggest that this advice is not effective. But looking at Table 6.1.11 it shows that in all 71 per cent of dentate adults claim to have seen a dentist in the last year. There are 40 million such people in the UK and if the survey's figures are correct then we would expect 28.4 million to be registered plus a number of the edentulous. The reality is that there are about 19.5 million adults registered.

There are, interestingly, only about one million more examinations (Item 1a) carried out and even fewer scalings (Item $3 a$ ). The average frequency of examinations is just under a year and for scaling well over a year. Any savings from reducing the frequency of examinations or scalings would have little effect on the level of expenditure on these items. There is little evidence from the Dental Practice Board's figures to support Professor Sheiham's estimate of 'a saving of between

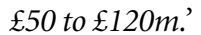

It may be that once a year cleaning 'has questionable health benefit'; or that 'intervals between recalls should be increased.' It may well be the NHS should not pay for additional examinations for the so-called 'worried well', or for a scale and polish because the patient is going to a wedding. As Professor Sheiham implied in his lecture, the National Institute for Clinical Excellence could well be the proper forum for such a debate, but not surely the pages of a newspaper or over the airwaves.

\section{Orthodontics on TV}

Sir, - Following the correspondence in the $B D J$ on orthodontics from Drs Muir and Greaves, ${ }^{1}$ especially after the Channel 4 Dispatches television programme and the article by Rob Chate, ${ }^{2}$ I felt that I would add some personal comments on the broader picture in orthodontics, as I suspect it is presently of great concern to the GDP with a special interest in the subject.

In my view much of the content of $\mathrm{Dr}$ Chate's article was the re-presentation of a previous 1994 article about British GDPs, which was published in America. ${ }^{3}$ Dr Chate took a series of articles from a 1992 edition of Dental Practice, ${ }^{4,5}$ and some seven years later took each article to task. I have now read some 100 of the referenced papers. While Dr Chate's single phrase summary is invariably valid, it is interesting to note that many of the articles are not wholly supportive of Dr Chate either, in that the authors acknowledge a lack of evidence based knowledge in the context of a range of opinion.

The $B D J^{\prime}$ s leader ${ }^{5}$ broadened the issues. $^{6}$ There is much evidence to support a growth directed philosophy in orthodontics. The current issue of the specialist interest journal $\mathrm{Cranio}^{7}$ contains what arguably is a core definitive list to counter that of Dr Chate. It is true to state that not all the answers are known. But as was so lucidly stated in the leader, 'when a dentist incorrectly selects a treatment option...then a human may suffer irreparable damage.' In my book, that rather beautifully sums up orthodontic extractions in a caries-free child.

The Dispatches programme and articles of its genre are simply a means to open up an argument, which has been full circle at least twice in 80 years. However, the broad contention remains. How can it be right to simply align a reduced number of teeth in diminished facial structures? While dental compromises have validity, our orthodontic goal must be to restore the face and teeth to full form and complete function. Since structures other than teeth are involved in the final position of those teeth, it must also ultimately be an orthopaedic goal.

The BOS is solid in its PR in the 'post-Dispatches' argument and is to be congratulated. I do worry at what I regard as the dismissive tone of the letter ${ }^{8}$ from the BOS Media Committee. To hear the BOS referring to 'rebel' dentists as though they are some band of mountain partisans makes me wonder what the BOS's fear actually is.

Fortunately, there appears to be broad agreement that it remains important to understand the diagnosis and correctly use the available orthopaedic and orthodontic tools to achieve the end result of the famous 'six keys' based upon evidence of what therapies can succeed. It does seem, however, that what is not part of the six orthodontic keys is the three dimensional relationship of the finished dental system beneath the cranium.

The BOS somewhat quirkishly fail to acknowledge that many of its members already practice a broad range of skills in the orthopaedic and orthodontic field. While one might argue the mechanics and the origins of the pathology requiring treatment, there is actually little controversy about the therapeutic goals. Perhaps one day the orthodontic mountain rebels will be welcomed down, as it is realised that we have all been fighting a common enemy, namely a developed-world disease of incomplete facial development associated with lifestyle more than evolution.

But as Desmond Tutu has titled his book, there can be no reconciliation without forgiveness - on both sides.

\section{Lister}

\section{Somerset}

1 Muir J D, Greaves R S. Silence surprising? $B r$ Dent J 2000; 189; 2

2 Chat R. Do we really want a quick fix? $\mathrm{Br}$ Dent $\mathrm{J}$ 2000; 188; 177

3 Chate R. The burden of proof: A critical review of orthodontic claims made by some general practitioners. Am J Orthod Dentofac Othop 1994 ; 106, 96-105

4 Fennel, Dent Prac 1992; 30

5 Frost, Dent Prac 1992;31

6 Grace M. Now you see it ... Br Dent J 1999, 188; $4: 173$

7 Cranio, Summer 2000

8 Sandler J. Research discredits rebel dentists. $\mathrm{Br}$ Dent J 2000; 188: 3

\section{Teeth whitening}

Sir - I refer to the recent paper (BDJ 2000 188: 11: 620-624) that was placed under a heading of 'Bleaching'. Surely this was incorrect as the paper concerned 'whitening' properties of a group of toothpastes. Was this a Freudian slip to emphasize the recent changes regarding home bleaching?

The study tested stain removal efficacy. However I am not aware of any studies to show that patients will sit for five minutes with their teeth covered in toothpaste. I always understood that the toothbrush acting with the paste was the vehicle for removal of stain.

A number of studies have been published showing the stain removal properties of low abrasive products and all of these used a toothbrush to remove stain that had first been lifted from the surface. However if we now have a product that works without a brush its use in the household market is long overdue. $1,2,3$

Just think - a light smearing over the bath and sink - leave for five minutes and wash away. Housework even a man could manage.

\section{G. Bamby \\ Middlesex}

1 Yankell S L. Laboratory Evaluations of Three Dentifrices with Polishing or Brushing. J Clin Dent 1998; 9: 61-63,

2 Habib C M. Preliminary Report: Laboratoryinduced Stain Removal as Assessed by 
Environmental Scanning Electron Microscopy. J Clin Dent, 1998; 9: 64-66,

3 Kleber C J. Laboratory Assessment of Tooth Whitening by Sodium Bicarbonate Dentifrices. J Clin Dent 1998; 9: 72-75,

The author Professor Martin Addy responds: The paper was placed, presumably by the editor, under a page heading of 'bleaching' which I would agree was inappropriate.

The more important comments on the study protocol deserve comment at greater length. As stated in the title and the body of the manuscript, the method was conceived to assess chemical stain removal. Virtually every toothpaste used on a toothbrush has the potential to remove stain by virtue of contained abrasives. We were interested in the ability of toothpastes to chemically remove stain for two reasons. Firstly, toothpastes and in particular some 'whitening' products contain ingredients which could remove stain by a non-abrasive chemical action: a notable example common to the majority of toothpastes would be sodium lauryl sulphate. Secondly and comparable with chemical plaque control, we were interested in the potential adjunctive benefits of the toothpaste to stain removal i.e. from sites not normally or easily brushed. The five by one minute exposure times were chosen again for two reasons. Firstly, in developing the model, we had noted that in the positive controls the oxidising mouthrinses achieved a maximum effect after five minutes. Secondly, we felt treatments each minute would be consistent with a tooth brushing time common to many individuals. Finally the idea of stain control without a toothbrush is already a concept since 'whitening' mouthrinse products are available over the counter.

\section{Mixed Messages}

Sir, - I have recently read an excellent Dental Health School Programme (sponsored by Colgate) written by Professor E J Kay which contains a 'Toothbrushing Record' chart to be signed off after the child has brushed twice a day: after breakfast and before bed.

Recently too, I have read a press release issued by the British Dental Health Foundation carrying the headline 'Don't Brush After Breakfast Warning in National Smile Week'. This press release, by the way, carries no scientific references to back up their socalled 'warning'.

Now, which is it to be? Before or after? As a dental hygienist, I frequently clean out fissures, of first permanent molars, (with a probe) of sweetened breakfast cereal before placing a fissure sealant. Equally, I see many (usually middle class, middle age women) patients exhibiting erosion almost certainly exasperated by brushing enthusiastically after the consumption of breakfast fruit and juices.

Dental professionals tailor their message to their patients. Can we not have a message going out: brush twice a day with a fluoride toothpaste.

\section{Clitter \\ Camberley}

\section{Special needs dentistry}

Sir, — Last year I changed the title of my consultancy from 'Oral Surgery' to 'Special Needs Dentistry.' The definition of 'special needs' tends to confuse many in the profession, but I have no problem with it - basically those poor people (and there are many) who, by reason of their disability, are not able to obtain dental treatment in the primary care sector or even in a hospital. They are passed around, until someone thinks of me, their last hope. Prior to my appointment in oral surgery, I was a senior registrar in restorative and I have a degree in medicine. These qualifications are ideal for comprehensive oral healthcare of special needs patients, a sort of one stop shop.

Visionaries in the nation have already appointed consultants and even one professor in special needs dentistry, others are close to doing so and enlightened institutions are offering MSc courses and diplomas. I believe that I am now the first consultant in special needs dentistry to retire. This has caused great philosophical problems, especially in Bristol where understandably there is a perceived need to adhere to the tenets of 'clinical governance.' The argument runs like this. You cannot appoint someone to a consultant post unless they have a Certificate of Completion of Specialist Training (CCST) or are a registered GDC specialist. But there is no such thing as a CCST in special needs dentistry, neither is there a specialist list. Well, they say, the candidate must be accredited in something so we are going to search the existing specialties and favour restorative (presumably on the grounds that fillings are involved.) Are there any accredited restorative specialist registrars who have the slightest real interest in special needs? Will a surgical dentist do? Or an endodontist? Where does experience, expertise and commitment come into the equation? Any person aspiring to a career in special needs should face the fact that they may be regarded as a Jack-of-all-trades, master of none and placed in the dogsbody grade.

There is now a proposal to have a senate of dental specialties but the membership does not include special needs or behavioural sciences. This proposal circumvents a large population of under-privileged, sick, fright- ened, wretched people who have a weak voice. It perpetuates the narrow, highly prescriptive range of 'specialities' that have a basis in technical skills for the mouth and ignores changes in people, society and disease. My perception is that the dental profession is ill-prepared for the incoming grey tide, of which I am now a member, and will soon be drowning not waving. There will be more geriatrics with teeth, more neurodegenerative disease, more medical problems, more tumours, more pain, in fact more special needs. For goodness sake, let us do something about it.

\section{Griffiths}

Bristol

\section{Scleroderma presents as facial hypoaesthesia}

Sir, - I write to describe an interesting case of scleroderma presenting as facial hypoaesthesia, which highlights the need for occasional lateral thinking in general dental practice.

A 61-year old lady was referred to our department by her GDP with a 10 week history of the sudden onset of numbness over the right cheek, in the distribution of the maxillary division of the trigeminal nerve. No history of trauma or associated dental and orofacial sepsis was elicited and apart from longstanding problems with osteoarthritis, her medical history was unremarkable. The patient was a nonsmoker and rarely drank alcohol. All other cranial nerves were intact.

Over the following three months, her symptoms spread to involve the tissues supplied by the mandibular division of the trigeminal nerve (the right chin region), as well as the tissues on the contralateral side (the left lower eyelid). An MRI scan of her brain was normal.

Approximately four months after this initial referral by her GDP, the patient was referred independently by her GMP to a consultant vascular surgeon, complaining of a two week history of the second and third fingers of both hands becoming cold, blue and intermittently numb, especially during activity. She gave no past history of Raynaud's phenomenon or any other atherosclerotic manifestations of disease. Her chest $\mathrm{x}$-ray was found to be normal and routine blood tests, including an immunology screen, were requested. These results revealed her anti-nuclear factor (ANF) to be positive, suggesting the possibility of a connective tissue disorder.

Over the ensuing three weeks, she continued to experience episodes of stiffness affecting her right arm and started to complain of dysphagia and weight loss. An 
urgent gastroscopy revealed the presence of grade three oesophagitis and small healing ulcers in both the gastric antrum and the first part of the duodenum. Histology confirmed the presence of helicobacter in moderate numbers and an active superficial chronic gastritis, but no evidence of malignancy. She was promptly started on the appropriate eradication therapy.

In the absence of an obvious surgical cause of her symptoms, the patient was then referred for a rheumatology opinion as to whether an underlying collagen vascular disorder might be giving rise to her symptoms of presumed Raynaud's phenomenon. In the interim, a further assessment by a consultant neurologist failed to shed any further light on the aetiology of these symptoms. At the rheumatology out-patient appointment, her immunology screen was repeated (five months after the initial series of blood tests). This later confirmed her ANF to be positive with a titre of 640 in a speckled pattern. She was also found to be highly positive to anti-scl 70 with a titre of $>100$ (normal range $<25 \mathrm{U} / \mathrm{ML}$ ). This autoantibody is found in 15-20 per cent of cases of scleroderma, for which it is a specific marker and is frequently associated with the more severe form of the disease. A skin biopsy was undertaken and this demonstrated appearances consistent with those of scleroderma.

One year and four specialities later the diagnosis had at last been made. It is now therefore apparent that the cause of the acute onset facial paraesthesia for which the patient was originally referred by her GDP, was a mononeuritis related to her scleroderma. Other non-automuimune causes of this type of clinical picture include: diabetes, Vitamin B12 deficiency, alcohol, trauma and syphilis. The patient remains under ongoing medical management.

\section{N. Shaun Matthews}

Fife

\section{Bored meeting?}

Sir, - I have to admire the honesty of H. W. Noble (Br Dent J 2000, 188; 9: 470) for admitting that falling asleep during lectures is very much on his agenda.

I often wonder what the best tactic to adopt is when confronted (as I have been on several occasions) by members of one's audience enjoying a blissful rest. Is it best to speed up, so as to minimise the time spent looking an insult in the face? Or should one actually slow down to allow the poor soul(s) to get a decent kip? Maybe a brisk announcement of an unscheduled tea/coffee break is best to allow the sleepy party to revive themselves immediately. Or perhaps a burst of strident rhetoric is appropriate to shock the inert into life. At all events, I hope Mr Noble chooses some obscure dark corners to snooze in, so as to give his lecturers the impression that they are really rather riveting after all.

\section{Stillman-Lowe}

Reading

\section{Anti antibiotics?}

Sir, - I hope that the title I have given to this letter might at least encourage colleagues to read it and reply to what on the surface appears to be a controversial statement. Obviously antibiotics have an important part to play in our profession both in treatment and prevention, but my concern is that they are often unnecessarily used. In fact we received a directive a little while back that dental and medical practitioners need to consider carefully whether antibiotics are appropriate to reduce the likelihood of resistant strains.

Sadly, we are often tempted to use antibiotics to treat a condition because of lack of time - either in the middle of a busy day or out of hours. My staff no doubt wish they could have a pound every time I have said to a patient that I rarely give antibiotics as I would rather treat the condition which invariably involves four procedures; extraction, pulp extirpation, tooth dressing with a sedative dressing and packing an infected socket. On many occasions patients have presented with acute pain and severe swelling. Antibiotics will eventually improve the situation but extraction, often using an intraligamentary technique or drainage though root canal, will give instant relief as well as avoid another visit and antibiotics.

I was prompted to write this letter after a recent, but not unusual, occurrence. I saw a patient who the day before had been seen by a practitioner on a Bank Holiday because he had very severe toothache - he was a reasonably regular attender. The practitioner gave antibiotics and just placed some temporary dressing over a very carious cavity. That night the patient was in even worse pain and saw me next day in a desperate state. The tooth just had to be extracted due to extensive caries, which I did in less than 10 minutes and the patient described the relief after the anaesthetic had worn off, as exquisite.

Please can we do all we can to provide our patients with as quick a relief as we can, even if it means running late, missing some of our lunch hour or being 15 minutes on a reopen surgery rather than five. That will greatly reduce the need to prescribe antibiotics as well as giving us the professional satisfaction of a job well done!

P. Williams

Lowestoft

\section{Is need enough?}

Sir, — Having read your leader 'Is Need Enough?' (Br Dent J 2000; 188; 10; 525) am I to deduce that Mike Grace favours a return to the profession's barber-surgeon roots in the market place? Dentistry's century long dalliance with professionalism is to end up at the hairdressers (dentures equal wigs).

It does not have to be so. Focusing on what patients want and what dentists consider they need are not mutally exclusive ('a different philosophy'). Reconciling them is indeed an art and science already. It is called good practice, not marketing. The profession's commitment to improve this fundamental skill comes under clinical governance.

\section{J. Hogan}

\section{Middlesex}

\section{Emergency calls}

Sir, - I feel that it is important that other members using the BT Voicebank service for our out-of-hours emergencies should be aware that BT Voice Messaging do not recommend this service for emergency helpline scenarios. This came to light following repeated failures of the system used by myself.

\section{J. D. Read}

Bolton

\section{Treatment under CPR}

Sir, - We are all very familiar with dental treatment under LA, GA, IV, RA but not so CPR.

Recently, I had arranged for some CPR training for my staff one evening and the following day, while treating my first patient, mentioned to my dental nurse what a valuable session it was. I always like to include patients in conversation, so rather light heartedly said to my long-standing patient that if she were to have a cardiac arrest, she would be in good hands!

Quick as a flash, she replied that in the event of it happening, could I please make sure I finished the treatment before we started resuscitation!

P. Williams

Suffolk

Please send your letters to: The Editor

British Dental Journal

64 Wimpole Street London WIM 8AL 